\title{
XBRL Acceptance in India: A Behavioral Study
}

\author{
Vineet Chouhan*, Shubham Goswami
}

Assistant Professor, School of Management, Sir Padampat Singhania University, Bhatewar, Udaipur, INDIA

*E-mail for correspondence: vineet.chouhan@spsu.ac.in

Received: Jun 20, 2015;

Accepted: Jun 30, 2015;

Published: Jul 24, 2015

Source of Support: Nil

No Conflict of Interest: Declared

\begin{abstract}
XBRL is fast becoming the new paradigm for reporting of financial information digitally. XBRL brings structure to business information with comprehensive description and contextual information for advanced analysis. It enhances the efficiency of financial reporting, accuracy, timeliness and reliability of financial data. Many Indian companies still resist using it. The present research uses technology acceptance model to analyze the perception of financial experts in respect of acceptance of XBRL as reporting method. The result revealed that using XBRL increases productivity but interacting with the XBRL requires lot of mental efforts. These findings can be an empirical and theoretical foundation to accelerate the adoption of XBRL in India.
\end{abstract}

Keywords: XBRL, financial reporting, technology acceptance, India

\section{INTRODUCTION}

\section{XBRL}

XBRL (eXtensible Business Reporting Language) reporting is gaining momentum as a medium of digital financial reporting (Ogundejiet.al, 2014). It is a meta-language, based on XML and used as electronic communication of business information. The primary purpose of XBRL is to facilitate the preparation, publishing, exchange, and analysis of financial statements. By using framework of XBRL it is possible to facilitate various kinds of reports that can be analyzed by computers efficiently (Vasarhelyi and Alles, 2008) and software applications (Silveira et al., 2007). XBRL can be considered as innovation as it is becoming an internet business standardization language (Willis, 2007). It doesn't change the financial reporting standards but change the way in which business and financial information is reported. Typically, an XBRL report consists of an XBRL instance document containing the financial facts and taxonomies that provide the information about how facts are interrelated in the financial statement. Taxonomy works as an electronic dictionary for business and financial terms within the business realm. Instance documents are business reports that are physically connected to taxonomies. It contains both numerical and non-numerical data and information about the data.

\section{XBRL in India}

The XBRL wave started in India in late 2007 when the Institute of Chartered Accounts of India (ICAI) initiated the idea of digital business reporting using XBRL with different regulators in India. XBRL implementation can achieve immediate benefits for Indian companies in terms of a more efficient means to file incorporation documents online and a simplified mode of filing of returns and forms. The benefits to Indian capital market include easy access to public information for users at any time and from anywhere, which may increase information transparency. With increased coverage, it is hoped that the XBRL data thus collected would significantly enhance the Government capability in policy formulation. Regulators, corporate as well as public and investors are also benefited at large. In India major regulators for XBRL adoption are Ministry of Corporate Affairs (MCA), Reserve Bank of India (RBI), Securities and Exchange Board of India (SEBI) and Insurance Regulatory and Development Authority (IRDA). From 31 ${ }^{\text {st }}$ March, 2011, Ministry of Corporate Affairs mandated XBRL reporting (in phases) for companies, to adopt the Industrial and Commercial Taxonomy developed by ICAI. In the first year (phase 1), the attention was on a fixed type of companies who are listed in India, with paid up capital of Rs. 5 crore and turnover of Rs. 100 crores, they will have to file their annual accounts (Balance Sheet and Profit and Loss account) in XBRL format from the FY 2010-11 onwards. The subsequent years witnessed a major change in the regulatory reporting format and a new schedule VI for improvement of financial statements disclosure system, which has enforced by the Companies Act 2013 with considerable changes in the taxonomy architecture. Similarly, the companies are required to submit their compliance report and cost audit report in XBRL format. Filers have the option to create their own XBRL documents in house or to convert their financial statements into XBRL format through outsourcing. Regardless of which approach, the first step is to tag each 
financial element to the published XBRL taxonomy so that accounting information can be converted into XBRL format. Once XBRL instance documents are created, filers need to validate the instance document before filing on MCA portal. Off-line process validates XBRL instance documents for business rules using the MCA off-line tool and for online validation (Pre-scrutiny), the instance documents are uploaded and validated from the MCA21 system (MCA 2012).

Regulators like RBI has also executed the XBRL based regulatory filings for banks using Internet and Indian Financial Network. The Ministry of Corporate Affairs (MCA) has adopted the XBRL taxonomy for Commercial \& Industrial (C\&I) Companies. SEBI and IRDA are in the process of implementing XBRL. But the adoption is not uniform across various sectors of businesses in India. As every organization faces some teething problems when adopting a new technology, the same holds true for XBRL. Firstly, XBRL has a steep learning curve to begin with. Therefore, there's a big challenge for the company to bring together a workforce skilled for using this new technology. It requires training efforts and change management initiatives on the company's part to prepare employees for such advancements. Organizations should also be careful about the probable effects of the technology adoption procedure on existing processes and people; and take necessary steps to minimize any adverse behavioral impact.

\section{ReseARCh OBJective}

Therefore adoption of XBRL becomes a relevant research area of interest among academics and practitioners (Pinsker, 2008; Muller, 2013). Researches around the world are carried from various disciplines on XBRL. Further, majority of academic XBRL research has focused on the US market (Srivastava and Liu, 2012) and, therefore, there is a need to see how non-US countries have implemented XBRL. Further, little research is cited regarding end-user attitude towards XBRL adoption (Muller, 2013). Analyzing the behavioral aspect of technology adoption, the present research has applied a technology acceptance model (TAM), by Davis (1989), to identify the predictors for attitude formation required for successful adoption of XBRL. Based on Baldwin (2006) study we classified the stakeholders for the system in four groups. The 'Standardizer' creates taxonomies, accounting standard, Legislator and regulator. 'Providers' are the companies, divisions that provide platform for creating reports. 'Intermediaries' are auditors, financial aggregators. 'Addresses' are Investors, regulators, managers. The present work attempts to analyze the acceptance of XBRL technology by 'Intermediaries' including auditors and company financial professionals responsible for preparation of XBRL report in Indian companies.Thus, the study has implications for auditors, as well as for firms who operate in India and in countries whose XBRL implementation reporting in mandatory.

\section{LITERATURE REVIEW: XBRL}

As pointed by many researchers, $\mathrm{XBRL}$ is used as most advanced and rigorous standards taxonomy developed to help for a better assurance of future digital financial reports (Cohen, 2009; Lymer and Debreceny, 2003; Boritz and Wo, 2008; Plumlee and Plumlee, 2008; Shrivastava and Kogan, 2009; and Gonzalbez and Rodriguez, 2012). XBRL adoption allows organisations to report quickly (Cohenet al., 2005), and standardised data to be accessed at a lower cost with greater transparency. With the adoption of XBRL, financial information can be optimized for creation, discovery, consumption, and reuse, and it also enables supply of information for business reporting to communicate among players more efficiently (Vasal and Srivastava, 2009; Debreceny et al., 2005). Additional XBRL benefits include cost savings because of increased data processing capability, decreased data duplication and decreased cost of bookkeeping (Pinsker and Li, 2008; Yoon,2011). Alles and Piechocki (2009) have developed a framework for understanding the use of tagged data for making change in the way in which decisions affecting governance are made. Roohani (2007) argues that XBRL would facilitate corporate governance and provide transparency to employees, investors and creditors, and regulators. Alles and Piechocki (2009) commented that XBRL will improve corporate governance. Premuroso and Bhattacharya (2008) confirm that operating performance and superior corporate governance related to their non-adopting peers in early and voluntary filers of financial information, was demonstrated under XBRL format. But Doolin and Troshani (2007) believed that benefits of XBRL are not expected to be immediate but will accumulate over time.

Tornatzky and Klein (1982) and Rogers (2003) suggest that the compatibility, complexity, relative advantage, and the ability to trial and observe a technology like XBRL, all play a significant role for decision regarding the adoption. The relative advantage and benefits of new technology is typically evaluated by Potential adopters against the perceived costs (Doolin and Troshani, 2007; Oliver and Whymark, 2005; Premkumar et al., 1994). Adopters will evaluate the initial and ongoing adoption cost of the technology (Rogers, 2003) against potential benefits such increased competitive advantage and as a reduction in compliance costs (Oliver and Whymark, 2005). The better the perceived positive relative advantage, the more likely an organisation will adopt the technology. Chartered Accountants will be primarily responsible for the implementation of XBRL in an organization (Gauri, 2014). Current study examines the factors that end user (filer) individual decision to accept XBRL using Davis (1989) Technology Acceptance Model (TAM).

\section{TECHNOLOGY ACCEPTANCE}

Due to complexity and context-sensitiveness, technology adoption required various models and which has speculated in the past two decades to specify the factors influencing organizations technology adoption (Wolfe, 
1994; Jeyaraj et al., 2006; Doolin and Troshani, 2007). These include the technology acceptance model (TAM) (Davis, 1989), TAM2 (Venkatesh et al., 2003), theory of planned behaviour (Ajzen, 1991), innovation diffusion theory (Rogers, 2003), and the unified theory of acceptance and use of technology (Venkatesh et al., 2003). Among all, TAM is the most popular model build upon a well-known theory of IS (Information System) research.

The literature of IT adoption relates to various Personal factors (Davis, 1989; Troshani and Doolin, 2005; Venkatesh, and Davis, 2000), Technological factors, Environmental factors and organisational factors (Troshani and Doolin, 2005). Personal factors include dimensions of TAM (Technology Acceptance Model) like perceived ease of use and perceived usefulness, attitude towards technology, which were proven to be more successful in measuring the impact on technology adoption. Technological factors including relative advantage (Zaltman et al. 1973), complexity (Rogers, 1983), compatibility (Kwon and Zmud, 1987), observability (Rogers, 1983), and trial ability (Venkatesh, and Davis, 2000). Technology complexity includes the current knowledge and skills of the employees in the organization (Doolin and Troshani, 2007). Davidson el al. (2006) and Rogers (2003) revealed that lack of knowledge and skills hinders the adoption of XBRL by organisation accountants. Environmental factors include external pressure (Iacovou et al., 1995) and competition (Grover, 1993), Innovation Adoption (Tornatzky and Klein,1982; Rogers, 1983). Organisational factors include top management support (Rai and Howard, 1994; Thong and Yap, 1995), organisation structure (Lai and Guynes, 1994), centralisation and formalisation (Zmud, 1982; Grover and Goslar, 1993), organisation size (Grover and Teng, 1992). But with present research scope, we only examined the impact of personal factors defined in Technology Acceptance Model (Davis, 1989).

\section{ReseARCH MOdel}

TAM is an adaptation of theory of reasoned action (TRA) by Fishbein and Ajzen (1975) and was mainly designed for modeling user acceptance of information technology in the workplace (Davis, 1989; Davis et al., 1989). The positive relationship between behavioral intentions and actions is extensively described by the theory of reasoned action (Azen,1980) and the theory of planned behavior (Azen, 1991). The TAM model assumes that system use is directly determined by behavioral intention to use the system which is in turn influenced by users' attitudes toward using the system and the perceived usefulness of the system. This model displays a high level prediction power of technology use (Goswami, 2014). The present research uses the TAM (Technology Acceptance Model) model proposed by Davis (1989) to understand the acceptance in respect of perceived usefulness and ease of use dimensions. Both are most closely related to the characteristics of the XBRL system. Perceived usefulness (PU) is the degree of personal believes that use of a particular system would enhance his or her job performance (Davidson et.al, 2006). Perceived ease of use (PEOU) is the degree to which a person believes that using a particular system would be free of effort.

Figure 1: Research Model

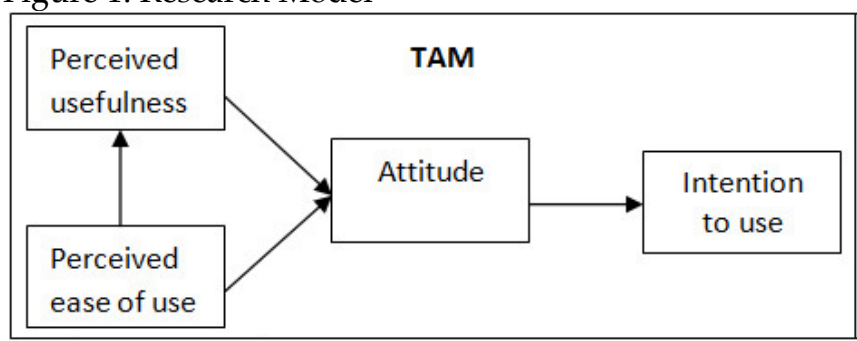

\section{Research Methodology}

Data collection tool- primary data is collected from a structured questionnaire. Each participant was asked to indicate his or her agreement or disagreement with each statement of questionnaire on a 5-point Likert scale with the end points being "strongly disagree" and "strongly agree". Majority of scale items acting on the survey were adapted from scales measuring variables in Davis et al. (1989), some of the items were also selected as per the literature review and pilot survey. The same are shown in Appendix.

Measures Reliability: Internal validity and consistency of the scale items are analysed for each variables. Hair et al. (2006) recommended that Cronbach alpha values from 0.6 to 0.7 were deemed the lower limit of acceptability. Cronbach's alpha reliability scores were all over 0.65, which is considered good (Nunnally, 1978). Hence, the results demonstrate that the questionnaire is a reliable measurement instrument.

Table 1: Scale reliability indicators

\begin{tabular}{|l|l|}
\hline Scale & Cronbach's alpha \\
\hline Perceived ease of use & 0.69 \\
\hline Perceived usefulness & 0.71 \\
\hline Attitude towards using & 0.66 \\
\hline Intention to use & 0.65 \\
\hline
\end{tabular}

Sampling - the sample of 105 financial professionals working in various companies in NCR region of North India was selected using convenience sampling. These respondents include charted accountant (CA), financial executive, auditors, company secretaries (CS) and others who are directly or indirectly involved in financial reporting in XBRL.

Hypothesis- In accordance with the research objectives of the paper, the data was collected on dimensions of perceived ease of use, perceived usefulness, end -user attitude and user behaviour intention to use XBRL as tool for digital financial reporting. Subsequently following hypothesis was developed: 
$H_{1}$ : Perceived ease of use has a significant effect on the perceived usefulness of the system.

$\mathrm{H}_{2}$ : Perceived ease of use $\mathcal{E}$ Perceived usefulness has a significant effect on attitude towards XBRL.

$H_{3}$ : Attitude towards using has a significant effect on intention to use XBRL.

\section{RESULTS}

Descriptive statistics collected from the survey showed the majority of the subjects were computer-savvy. Slightly over half of the respondents (65 percent) were male, and the respondents' age varied from 23 to 37 years $($ Mean $=26.4$ years, $\mathrm{SD}=0.702$ ), reflecting the population from which sample was drawn. The survey consist large proportion of financial executives (65 percent) as compared to CA (10 percent), CS (14 percent) and others (11 percent). No significant correlation was found between participants' age, gender and designation and the two dependent variables namely, attitude and intention to use. These demographic variables were dropped from further analysis.

Linear regression analysis is conducted to test the hypothesis 1 based on completed surveys data. In a regression analysis the perceived ease of use is defined as an independent variable and perceived usefulness is defined as dependent variable. Table 2 presents the regression results used to test $\mathrm{H}_{1}$.

Table 2: Regression result for $\mathrm{H}_{1}$

\begin{tabular}{|c|c|c|c|c|c|}
\hline Variables & $\begin{array}{c}\text { Standardized Beta } \\
\text { Coefficients }\end{array}$ & $\begin{array}{c}\text { Std. Error of the } \\
\text { Estimate }\end{array}$ & t-Statistics & p-value $^{\text {Adjusted R }}{ }^{2}$ \\
\hline Perceived ease of use & .646 & 1.015 & 3.586 & 0.002 & .384 \\
\hline
\end{tabular}

Dependent Variable: Perceived Usefulness, ANOVA: $12.860(\mathrm{p}=0.02)$

As clear from the above table, perceived ease of use had a significant influence on perceived usefulness $(\beta=.646 ; \mathrm{p}$ $<0.05)$, which further confirm the validity of hypothesis 1 . To test the Hypothesis 2, both independent variables i.e. perceived ease of use and perceived usefulness is regressed on attitude towards using the XBRL system. Result from the table 3 , it is evident that constructs of both ease of use (EOU) and perceived usefulness (PU) have significant impact on attitude formation of end-user regarding XBRL. The mean values of descriptive statistics shows a less favorable attitude towards XBRL filing. Furthermore the regression model is able to extract four predictors that explain about 73 percent of variance in dependent variable i.e. attitude towards XBRL usage.
The ANOVA analysis provides the statistical test for overall model fit in terms of F Ratio. The total sum of squares (31.800) is the squared error that would accrue if the mean of XBRL Implementation has also been changed to predict the dependent variable. Respondent shows that their low attitude towards acceptance of XBRL is broadly due to the increased mental effort require for interacting with the reporting system. They have to consult the manuals frequently for registering the financial data to match with the taxonomies. Although the result also confirms that filers (end-users) believe that using XBRL will improve the effectiveness and quality of work in long run.

Table 3: Multivariate Regression Analysis for $\mathrm{H}_{2}$

a. Descriptive Statistics

\begin{tabular}{|c|c|c|c|}
\hline Variables & Mean & Std. Deviation & N \\
\hline Attitude & 2.900 & 1.293 & 105 \\
\hline EOU & 3.642 & 1.011 & 105 \\
\hline PU & 3.270 & 0.802 & 105 \\
\hline Behaviour & 2.950 & 1.276 & 105 \\
\hline
\end{tabular}

b. Regression Model results
\begin{tabular}{|c|r|r|r|r|}
\hline Variables & $\begin{array}{c}\text { Standardized Beta } \\
\text { Coefficients }\end{array}$ & $\begin{array}{c}\text { Std. Error of the } \\
\text { Estimate }\end{array}$ & t-Statistics & p-value \\
\hline Constant & 1.202 & 1.674 & 1.238 & .235 \\
\hline PU_2 & .572 & 1.015 & -3.855 & .000 \\
\hline EOU_1 & -.464 & .834 & .002 \\
\hline PU_7 & .348 & .742 & -2.150 & .015 \\
\hline EOU_4 & -.258 & .670 & .048 \\
\hline Sum square (Total) & & 31.800 & Adjusted R ${ }^{2}$ & \\
\hline$R^{2}$ & .788 & p-value (F) & .731 \\
\hline F-Statistics & 13.939 & & $.000^{\mathrm{b}}$ \\
\hline $\begin{array}{l}\text { a. Dependent Variable: Attitude } \\
\text { b. Predictors: (Constant), EOU_1, PU_2, EOU_4, PU_7 }\end{array}$ & & \\
\hline
\end{tabular}


To test the hypothesis 3, third linear regression is applied. On the contrary to TAM hypothesis, the result shows that attitude was found to have no effect on intention to use. The model appeared to have relatively weaker utility for explaining intention development. An explanation of this might be that respondents are willing to adopt beneficial applications, but awareness programs, product training on new taxonomies, and top management support is essential for solidifying perception into future usage.

Table 4: Regression result for $\mathrm{H}_{3}$

\begin{tabular}{|c|c|c|c|c|c|}
\hline Variables & $\begin{array}{c}\text { Standardized Beta } \\
\text { Coefficients }\end{array}$ & $\begin{array}{c}\text { Std. Error of the } \\
\text { Estimate }\end{array}$ & t-Statistics & $\mathrm{p}^{2}$ value & $\mathrm{R}^{2}$ \\
\hline Attitude & -.322 & 1.258 & 1.443 & 0.116 & .054 \\
\hline
\end{tabular}

Dependent Variable: Intention to use, ANOVA: 2.081(P>0.05)

\section{Conclusion and Recommendation}

The present research begins with a clarification that global adoption of XBRL will have a large impact on financial and corporate reporting process. Indian companies can also be benefited with this technology innovation along with its inherent operational advantages. TAM has proven to be a useful acceptance model in helping to understand and explain the user behavior in XBRL implementation. The study examined the effect of perceived usefulness and ease of use on attitude of Indian financial professionals towards XBRL reporting. The empirical result shows that perceived ease of use is an important determinant for formulating perceived usefulness. In accordance with Davis (1989) assumption, current research also postulates a significant influence of perceived usefulness and perceived ease of use on attitude towards using the technology. The research findings also outline some broad reasons for slow adoption of XBRL in Indian context. The end-users confirms that using XBRL will improve the effectiveness and quality of their job but technological complexities and lengthy process for matching financial data with given set of taxonomies is making system less interesting to accept. Staying up to date with current taxonomies is also essential.

Moreover, Change management is also a crucial step to be taken before implementing a technology like this. Employees are quite reluctant for changes in processes. This makes it imperative for companies to conduct change management initiatives and regular trainings which help employees embrace the change openly. The implementation roadmap must be charted out with detailed planning for the technology's adoption. It is critical to ascertain the most suitable method for your organization to implement it. Your decision to go for bolt-on, or outsource or built-in approach must be carefully thought of and minutely planned keeping in mind the organization needs.

\section{Research limitations}

The present research also based on certain assumptions which limits the scope of study. The study restricted by generalisability of findings because of small sample size and assumption that they adequately represents typical Indian customer. Contrary to TAM hypothesizes, attitude was found to have no effect on intention to use. Compared with prior TAM studies, the model appeared to have relatively weaker utility for explaining attitude formation and intention development. The present work is a perception study for 'intermediaries' or filers regarding acceptance of XRBL. Hence, it limits in presenting an overall view of other stakeholders including companies, software providers, and regulators in the adoption process.

\section{Future Research}

It is worth noting that XBRL has exhibited capabilities to produce the digitized version financial statements, but it is still unable to capture information displayed through various other sections of the financial statements and the annual reports. Particularly, the information displayed through the notes to accounts and, management discussion and analysis sections of the annual reports. This is indeed a challenging area for future research. All aspects concerning the improvement of efficiency by applying XBRL like time savings, reduced effort, and improved communication are mentioned frequently in literature but hardly any research activities could be recognized. Future researches should focus on the evaluation of productivity of digital financial reporting. Other potential area of research is to analyze the impact of demographic factors and user experience upon the XBRL adoption among consumers must be examined. Based on our discussions and literature review, we suggest that research focus might also be on the economic impact of XBRL. This may help to present a clear business case to the stakeholders which should contribute to the comprehensive adoption of XBRL.

\section{REFERENCES}

Ajzen, I (1991). The theory of planned behavior. Organizational Behavior and Human Decision Processes, 50, 179-211.

Ajzen, I., and Fishbein, M. (1980).Understanding Attitudes and Predicting Social Behavior. Englewood Cliffs, NJ: Prentice-Hall

Alles, M., and M. Piechocki. (2009). Will XBRL Improve Corporate Governance? A Framework for Enhancing Governance Decision Making Using Tagged Data. Presented at 4th International Conference at The University of Kansas, Lawrence, KS, April 24-25.

Baldwin, A.A., Brown, C.E., Trinkle, B.S (2006). XBRL: An Impacts Framework and Research Challenge. Journal of Emerging Technologies in Accounting, 3, 97-116 
Boritz, J. and Wo, W. (2008).The SEC's XBRL Voluntary Filing Program on EDGAR: A Case For Quality Assurance.Current Issues in Auditing, 2(2), A36-A50.

Cohen E. (2009). XBRL's Global ledger framework: exploring the standardized missing link to ERP integration. International Journal of Disclosure E Governance, 6(3),188- 206.

Cohen, E. E., Schiavina, T., Servais, O., 2005. XBRL: The standardised business language for 21st century reporting and governance. International Journal of Disclosure and Governance, 2 (4), 368-394

Davidson, A., Robinson, A. and Malthus, S. (2006). Survey of chartered accountants show XBRL slow to catch on.Chartered Accountants Journal, 85(9), 68-70.

Davis FD, Bagozzi RP (1989). User acceptance of computer technology: a comparison of two theoretical models. Management Science, 35(8), 983-1003.

Davis FD. (1989). Perceived usefulness, perceived ease of use, and user acceptance of information technology. MIS Quarterly 13(3), 319-340.

Debreceny RS, Chandra A, Cheh JJ, Guithues-Amrhein D, Hannon N, Hutchinson PD, et al (2005). Financial reporting in XBRL on the SEC's EDGAR system: a critique and evaluation, Journal of Information Systems,19(2),191-210.

Doolin, B. \&Troshani, I. (2007). Organizational adoption of XBRL. Electronic Markets, 17(3), 199-209. Available: www.electronicmarkets.org.

Fishbein, M., \&Ajzen, I. (1975). Belief, attitude, intention and behaviour: An introduction to theory and research. Reading, Addison-Wesley.

Gauri, M. (2014). XBRL: In India. Global Journal of Finance and Management, 6(6), 517-522.

Gonzalbez, J.M. and Rodriguez, M. M. (2012).XBRL and Integrated Reporting: The Spanish Accounting Association Taxonomy Approach.The International Journal of Digital Accounting Research, 12, 59-91

Goswami, S. (2014), Understanding adoption of electronic G2C service: An extension to Technology Adoption Model, Pacific Business Review, 8(6), 36-44

Grover, V. (1993). An Empirically Derived Model for the Adoption of Customer-based Interorganizational Systems.Decision Sciences, 24(3), 603-640.

Grover, V. and Goslar, M. (1993). The initiation, adoption, and implementation of telecommunications technologies in U.S. organisations. Journal of Management Information Systems, 10(1),141-163.

Grover, V. and Teng, J. (1992). An examination of DBMS adoption and success in American organisations. Information and Management, 23(5): 239-248.

Hair, J. F., Black, W. C., Babin, B. J., Anderson, R. E., \& Tatham, R. L. (2006). Multivariate data analysis (Vol. 6). Upper Saddle River, NJ: Pearson Prentice Hall.

Iacovou, C. L., Benbasat, I., \& Dexter, A. S. (1995). Electronic data interchange and small organizations: adoption and impact of technology. MIS Quarterly, 465-485.

Jeyaraj, A., Joseph, R.W. and Lacity, M.C. (2006). A review of the predictors, linkages, and biases in IT innovation adoption research. Journal of Information Technology, 21, 1-23.

Khan S, Chouhan V, Chandra B, Goswami S (2014). Sustainable accounting reporting practices of Indian cement industry: An exploratory study - Uncertain Supply Chain Management, 2(2), 61-72

Kwon, T. H. and Zmud, R. W. (1987). Unifying the Fragmented Models of Information Systems Implementation.in R. J. Boland and R. Hirschheim (eds) Critical Issues in Information Systems Research, New York: Wiley, 227-51.
Lai, V.S. \&Guynes, J. L. (1994). A model of ISDN (integrated services digital network) adoption in U.S. corporations. Information and Management 26, 75-84.

Lymer, A. and Debreceny, R. (2003).The Auditor and Corporate Reporting on the Internet: Challenges and Intuitional Responses.International Journal of Auditing, 7,103-120.

MCA. (2012). XBRL filing manual version 2.0 for financial year 2011-2012. Released on October 14, 2012. Available at http://www.mca.gov.in/Ministry/pdf/ XBRL_Filing Manual _v2.0_14thOct2012.pdf

Müller-Wickop, N., Schultz, M., \&Nüttgens, M. (2013). XBRL: impacts, issues and future research directions. Enterprise Applications and Services in the Finance Industry, 112-130. Springer Berlin Heidelberg.

Nunnally, J.C. (1978). Psychometric Theory, (2nd ed.). New York: McGraw-Hill.

Ogundeji, M.G., Oluwakayode, E., \& Tijani, O.M. (2014). Critical factors of XBRL adoption in Nigeria: a Case for Semantic Model-Based Digital Financial Reporting. Computer Science and Information Technology, 2(1): 45-54, Available: http:/ / www.hrpub.org DOI: 10.13189/csit.2014.020105

Oliver, D. and Whymark, G. (2005). Researching ERP adoption: an internet-based grounded theory approach.Online Information Review, 29(6), 585-603.

Pinsker R, Li S (2008) Costs and benefits of XBRL adoption: early evidence. Commun ACM, 51(3), 47-50.

Plumlee, R. and Plumlee, M. (2008). Assurance on XBRL for Financial Reporting. Accounting Horizons, 22(3),353-368.

Premkumar, G., Ramamurthy, K. and Nilakanta, S. (1994). Implementation of electronic data interchange: an innovation diffusion perspective. Journal of Management Information Systems, 11(2), 157-86.

Premuroso, R. F., and Bhattacharya, S. (2008). Do Early and Voluntary Filers of Financial Information in XBRL Format Signal Superior Corporate Governance and Operating Performance?.International Journal of Accounting Information Systems, 9, 1 - 20.

Rai, A., and Howard G.S. (1994). Propagating CASE Usage for Software Development: An Empirical Investigation of Key Organizational Correlates.OMEGA: The International Journal of Management Science, 22(2), 133-247.

Rogers, E. M. (2003).Diffusion of Innovations, New York: Free Press

Rogers, Everett (2003). Diffusion of Innovations, 5th Edition. Simon and Schuster. ISBN 978-0-7432-5823-4.

Rogers, Everett M. (1983). Diffusion of Innovations. New York: Free Press. ISBN 978-0-02-926650-2.

Roohani, S. (2007). XBRL: Meeting Challenges of Corporate Governance Reporting and Documentation. Presented at 2007 International Conference at The University of Kansas, Lawrence, KS, May 11-12.

Shrivastava, R. and Kogan, A. (2009). Assurance on XBRL Instance Document: A Conceptual Framework of Assertions, www.ssrn.com: http://ssrn.com/abstract $=1289467$.

Silveira, C., Abreu, R., Fátima, D. (2007). From an ObjectOriented Approach to the Financial Reporting: An Open Architecture. The International Journal of Digital Accounting Research, 7, 1-25.

Srivastava, R. P. (2009). XBRL (Extensible Business Reporting Language): A Research Perspective. Indian Accounting Review, 13(1), 14-32.

Srivastava, R. P., and Q. Liu. (2012). Special issue of Journal of Information System on XBRL. Journal of Information Systems, 26 (1), 97-101. 
Thong, J. Y. L., Yap, C. S. (1995) CEO characteristics, organizational characteristics and information technology adoption in small businesses. International Journal of Management Science 23, 429-442.

Tornatsky, Louis G. \& Katherine J. Klein (1982). Innovation Characteristics and Innovation Adoption Implementation. IEEE Transactions on Engineering Management, 29(11), 28- 45.

Tornatzky, L. G. and Klein, K. J. (1982). Innovation Characteristics and Innovation Adoption Implementation: A Meta-analysis of Findings. IEEE Transactions on Engineering Management EM-29(1), 28-45.

Troshani, I. and Doolin, B. (2005). Drivers and inhibitors impacting technology adoption: a qualitative investigation into the Australian experience with XBRL. paper presented at 18th Bled e-Conference: e-Integration in Action, Bled, June 6-8.

Vasal, V. K., \& Srivastava, R. P. (2002). Extensible Business Reporting Language (XBRL): the digital language of business: an Indian perspective. Indian Accounting Review, 6(1), 41-59.

Vasal, V. K.; Srivastava, R. P. (2005). IT and web-based accounting, evidence from the Indian capital market. IIMB Management Review, 17(1), 79-85.
Vasarhelyi, M.A., Alles, M.G. (2008). Reengineering Business Reporting Creating a Test Bed for Technology Driven Reporting.The International Journal of Digital Accounting Research, 8, 97-135.

Venkatesh V and Davis FD (2000). A theoretical extension of the Technology Acceptance Model: Four longitudinal case studies. Management Science, 46(2), 186-204.

Venkatesh, V., Morris, M.G., Davis, F.D., and Davis, G.B (2003). User Acceptance of Information Technology: Toward a Unified View, MIS Quarterly, 27, 425-478

Willis, M. (2007). Improving Investor Communications and Analysis via Standardization. The International Journal of Digital Accounting Research,7, 151-163.

Wolfe, R.A. (1994). Organisational innovation: review, critique and suggested research directions, Journal of Management Studies, 31(3), 405-31.

Yoon H, Zo H, Ciganek AP (2011). Does XBRL adoption reduce information asymmetry? Journal of Business Research 64(2),157- 163

Zaltman, G., Duncan, R. and Holbeck, J. (1973).Innovations and Organizations. New York: Wiley.

Zmud, R. W. (1982). Diffusion of modern software practices: Influence of centralization and formalization. Management Science, 28, 1421-1431. 


\section{APPENDIX}

Table: Measur

ement Items used in the Study

\begin{tabular}{|l|l|}
\hline \multicolumn{1}{|c|}{ PCALCEIVED EASE OF USE } & CODE \\
\hline I need to consult the user manual often when using XBRL? & \\
\hline I find it easy to recover from errors encountered while using XBRL & EOU_1 \\
\hline It would be easy for me to find information from XBRL & EOU_2 \\
\hline Interacting with the XBRL requires lot of my mental efforts & EOU_3 \\
\hline My interaction with the XBRL is easy for me to understand & EOU_4 \\
\hline The XBRL is rigid and inflexible to interact with & EOU_5 \\
\hline My interaction with XBRL was clear and understandable & EOU_6 \\
\hline Overall, I find the XBRL easy to use & EOU_7 \\
\hline \multicolumn{1}{|c|}{ PERCEIVED USEFULNESS } & EOU_8 \\
\hline Using XBRL improves the quality of the work I do & \\
\hline Using XBRL gives me greater control over my work & PU_1 \\
\hline XBRL enables me to accomplish tasks more quickly & PU_2 \\
\hline Using XBRL increases my productivity & PU_3 \\
\hline Using XBRL improves my job performance & PU_4 \\
\hline Using XBRL allows me to accomplish more work than would otherwise be possible & PU_5 \\
\hline Using XBRL enhances my effectiveness on the job & PU_6 \\
\hline Overall, I Find the XBRL Useful & PU_7 \\
\hline & PU_8 \\
\hline Using XBRL is a good idea & \\
\hline I like the idea of using XBRL $\quad$ AT_1 \\
\hline I have a generally favorable attitude toward using XBRL & AT_2 \\
\hline Using XBRL is an appealing idea & AT_3 \\
\hline & AT_4 \\
\hline I intend to use XBRL services in the future & \\
\hline I will use XBRL regularly in the future & IU_1 \\
\hline
\end{tabular}

